\title{
The developmental process, feasibility and acceptance of the Grow It! app: a smartphone serious game for adolescents
}

Evelien Dietvorst, Michelle A Aukes, Jeroen S Legerstee, Annabel Vreeker, Micah

M Hrehovcsik, Loes Keijsers, Manon H J Hillegers

Submitted to: JMIR Formative Research

on: April 30, 2021

Disclaimer: () The authors. All rights reserved. This is a privileged document currently under peer-review/community review. Authors have provided JMIR Publications with an exclusive license to publish this preprint on it's website for review purposes only. While the final peer-reviewed paper may be licensed under a CC BY license on publication, at this stage authors and publisher expressively prohibit redistribution of this draft paper other than for review purposes. 


\section{Table of Contents}

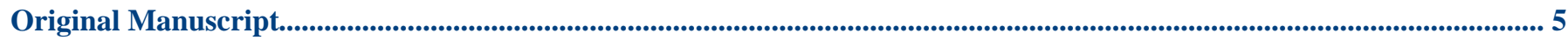

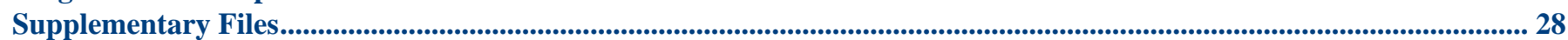

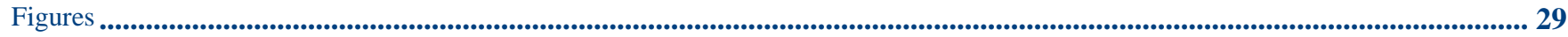

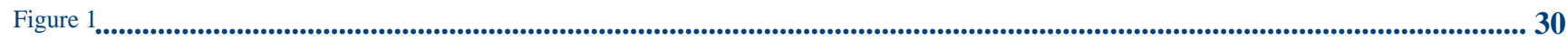

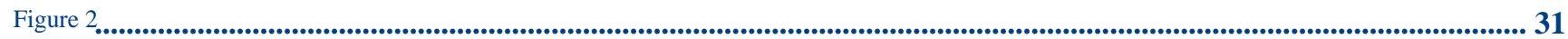

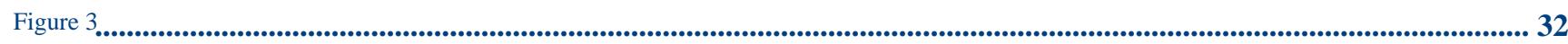

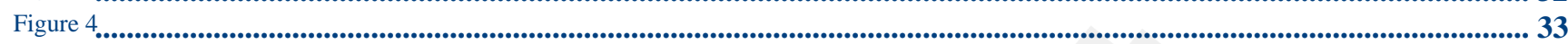

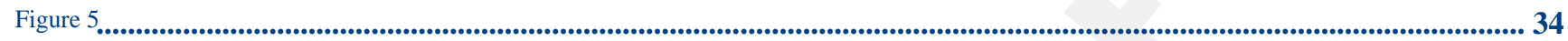

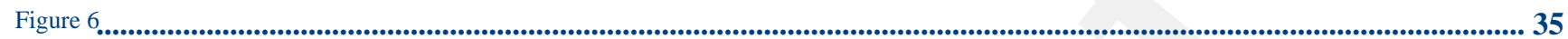

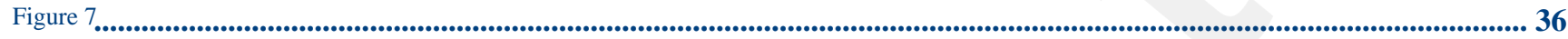

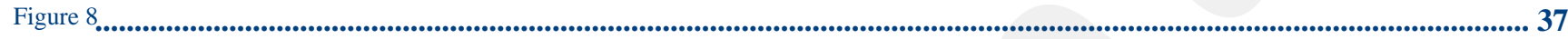

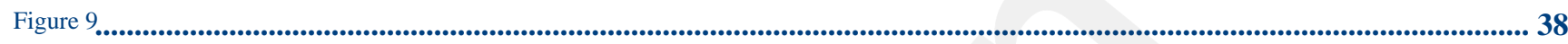

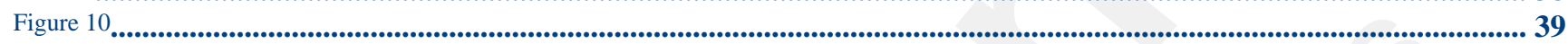




\section{The developmental process, feasibility and acceptance of the Grow It! app: a smartphone serious game for adolescents}

Evelien Dietvorst ${ }^{1 *}$ MSc; Michelle A Aukes ${ }^{1 *}$ MSc; Jeroen S Legerstee ${ }^{1} \mathrm{PhD}$; Annabel Vreeker ${ }^{1} \mathrm{PhD}$; Micah M Hrehovcsik $^{2}$ PhD; Loes Keijsers ${ }^{3}$ Prof Dr, PhD; Manon H J Hillegers ${ }^{1}$ Prof Dr, MD, PhD

${ }^{1}$ Department of Child and Adolescent Psychiatry/Psychology Erasmus MC Sophia Children's Hospital Erasmus University Medical Center Rotterdam NL

${ }^{2}$ Innovation Studio HKU University of the Arts Utrecht Utrecht NL

${ }^{3}$ Erasmus School of Social and Behavioural Sciences Department of Psychology Education \& Child Studies Rotterdam NL

"these authors contributed equally

\section{Corresponding Author:}

Manon H J Hillegers Prof Dr, MD, PhD

Department of Child and Adolescent Psychiatry/Psychology

Erasmus MC Sophia Children's Hospital

Erasmus University Medical Center

Wytemaweg 8

Rotterdam

NL

\section{Abstract}

Background: Anxiety and mood problems in adolescents often go unnoticed and may therefore remain untreated. Identifying and preventing the development of emotional problems requires monitoring and effective tools to strengthen adolescents' resilience, for example, by enhancing coping skills. The current study describes the developmental process and game mechanics of Grow It!, a multiplayer serious gaming app.

Objective: The aim of the Grow It! app is to (1) monitor behaviours, thoughts, and emotions in daily life by utilizing the Experience Sampling Method (ESM) to increase self-insights and (2) to offer daily cognitive behavioral therapy (CBT) inspired challenges to promote adaptive coping in adolescents from 12-25 years old.

Methods: Our approach entails an iterative game design process and an agile method to develop the smartphone app. The incorporated game features (ie, challenges, chat functionality, and visual representation) in the Grow It! app were co-designed with adolescents to increase participant engagement and adherence.

Results: The Grow It! app was delivered for Android and iOS in May 2020. Grow It! was offered to adolescents during the COVID-19 crisis between May and June 2020. Participants of the Grow It! COVID-19 study ( $\mathrm{n}=968,30.4 \%$ boys, M age = $17.3, \mathrm{SD}=3.4)$ completed on average 23.2 challenges $(\mathrm{SD}=23.5)$ of the available 42 challenges during 6 weeks. ESM compliance, however, was suboptimal (17\%). Surveys among 487 users indicated an overall score of 7.8 out of $10.74 \%$ would recommend the app to friends and $66 \%$ reflected more on their feelings.

Conclusions: To our knowledge, Grow It! is the first gamified ESM application, which contains integrated CBT-based challenges moreover. The Grow It! app obtained high user ratings and encouraged adolescents to be more physically active and reflect on their feelings. However, the integrated ESM tool needs further adjustment to increase compliance. Simultaneously, providing participants with feedback on their mood profiles would be an important feature for improving the app in the future.

(JMIR Preprints 30/04/2021:29832)

DOI: https://doi.org/10.2196/preprints. 29832

\section{Preprint Settings}

1) Would you like to publish your submitted manuscript as preprint?

$\checkmark$ Please make my preprint PDF available to anyone at any time (recommended).

Please make my preprint PDF available only to logged-in users; I understand that my title and abstract will remain visible to all users. 
Only make the preprint title and abstract visible.

No, I do not wish to publish my submitted manuscript as a preprint.

2) If accepted for publication in a JMIR journal, would you like the PDF to be visible to the public?

$\checkmark$ Yes, please make my accepted manuscript PDF available to anyone at any time (Recommended).

Yes, but please make my accepted manuscript PDF available only to logged-in users; I understand that the title and abstract will remain Yes, but only make the title and abstract visible (see Important note, above). I understand that if I later pay to participate in <a href="http 


\section{Original Manuscript}




\section{The developmental process, feasibility and acceptance of the Grow It! app: a smartphone serious game for adolescents}

E. Dietvorst*, MSc, Department of Child and Adolescents Psychiatry/Psychology Erasmus MC Sophia Children's Hospital, Erasmus University Medical Center, Rotterdam, The Netherlands (e.dietvorst@erasmusmc.nl)

M.A. Aukes*, MSc, Department of Child and Adolescents Psychiatry/Psychology Erasmus MC Sophia Children's Hospital, Erasmus University Medical Center, Rotterdam, The Netherlands (m.aukes@erasmusmc.nl)

J.S. Legerstee, PhD, Department of Child and Adolescents Psychiatry/Psychology Erasmus MC Sophia Children's Hospital, Erasmus University Medical Center, Rotterdam, The Netherlands (j.s.legerstee@erasmusmc.nl)

A. Vreeker, PhD, Department of Child and Adolescents Psychiatry/Psychology Erasmus MC Sophia Children's Hospital, Erasmus University Medical Center, Rotterdam, The Netherlands (a.vreeker@erasmusmc.nl)

M.M. Hrehovcsik, PhD, Innovation Studio, HKU University of the Arts Utrecht, Utrecht, The Netherlands (micah.hrehovcsik@hku.nl)

Prof. Dr. L. Keijsers, PhD, Erasmus School of Social and Behavioural Sciences, Department of Psychology, Education \& Child Studies, Rotterdam, The Netherlands (keijsers@essb.eur.nl)

Prof. Dr. M.H.J. Hillegers, MD PhD, Department of Child and Adolescents Psychiatry/Psychology Erasmus MC Sophia Children's Hospital, Erasmus University Medical Center, Rotterdam, The Netherlands (m.hillegers@erasmusmc.nl)

*These authors contributed equally and share first authorship 


\section{Corresponding Author:}

M.H.J. Hillegers, MD, $\mathrm{PhD}$

Department of Child and Adolescent Psychiatry/Psychology

Erasmus University Medical Center (Erasmus MC) Sophia Children’s Hospital

Wytemaweg 8

Rotterdam, 3015 CN

Netherlands

Phone: 010-7040209

Email: m.hillegers@erasmusmc.nl

\section{Abstract}

Background: Anxiety and mood problems in adolescents often go unnoticed and may therefore remain untreated. Identifying and preventing the development of emotional problems requires monitoring and effective tools to strengthen adolescents' resilience, for example, by enhancing coping skills. Objective: The current study describes the developmental process, feasibility and acceptance of Grow It!, a multiplayer serious game app for adolescents aged 12-25. The app consists of (1) Experience Sampling Method (ESM) to monitor thoughts, behaviours, and emotions in daily life to enhance self-insights, and (2) daily cognitive behavioural therapy (CBT) based challenges to promote adaptive coping. Methods: Our approach entails an iterative game design process combined with an agile method to develop the smartphone app. The incorporated game features (ie, challenges, chat functionality, and visual representation) in the Grow It! app were co-designed with adolescent end-users to increase participant engagement and adherence. Results: The Grow It! app was delivered for Android and iOS in May 2020. Grow It! was offered to adolescents during the COVID19 crisis between May and December 2020. Participants of the Grow It! COVID-19 study (sample 1: $\mathrm{N}=685$, mean age $16.19, \mathrm{SD}=3.11,28.2 \%$ boys and sample 2: $\mathrm{N}=1035$, mean age $18.78, \mathrm{SD}=3.51$, 18.7\% boys) completed 32\%-50\% challenges. Compliance of ESM was suboptimal (17\%-31\%). Follow-up questionnaires indicated an overall score of the app of 7.1 out of $10.73-76 \%$ would recommend the app to friends. Conclusions: To our knowledge, Grow It! is the first gamified ESM application measuring both individual differences in emotional dynamics and offering an integrated CBT-based intervention. Our findings support the feasibility and acceptance, and therefore applicability, of the Grow It! app in adolescents. Further iterations of this serious-game app will focus on the increase of compliance and on providing participants feedback through their personal 
mood profiles.

Keywords: Ecological Momentary Assessment (EMA); serious game; CBT; depression; internalizing problems; adolescents; high risk; digital health; mobile health; mHealth; game design; application development 


\section{Introduction}

Internalizing problems, such as anxiety and mood problems, have a significant impact on young people’s lives. These internalizing problems are often associated with school dropout, reduced social functioning, loneliness, unemployment and reduced quality of life [1-3]. Anxiety and mood disorders usually begin in adolescence [4,5] and unfortunately, they often go unnoticed or untreated [6]. When persistent, internalizing problems often result in emerging psychiatric disorders affecting young people's daily lives, their future and society [1-3,6]. Therefore, early identification and timely intervention are crucial to prevent further deterioration, improve prognosis and reduce the burden on healthcare systems and society in general $[1,7,8]$. Mobile health (mHealth) can play an important role in accurate recognition of symptoms and timely treatment [9-11]. MHealth is defined as wireless technologies, such as smartphone applications, to support or achieve health objectives. In terms of its advantages, first of all mHealth is scalable, accessible, and maybe less stigmatising than traditional treatment for youths due to the level of anonymity and privacy [12]. Furthermore, mHealth offers the possibility to incorporate motivational elements such as playfulness and gamification, which is advantageous because humans supposedly learn best by playing [13-17]. Finally, mHealth offered in an attractive and fun way through adolescents' own devices fits very well with their daily life and activities [eg, 18,19]. Usage is flexible, as it is independent of time and place and can be at a selfdetermined pace, which is thought to enhance self-efficacy [12]. Indeed, most adolescents indicated that they would use an app to screen for emotional problems and treatment if available [20]. Even though there are already several mHealth apps [eg, 21], preventive mHealth applications that integrate novel methods for early identification and preventive intervention are still lacking.

A promising method for the early identification of emotional problems is the Experience Sampling Method (ESM). ESM is a structured dairy method, in which participants obtain multiple random notifications on their phone during the day. When a notification pops up, they fill out a microquestionnaire in which they report on their behaviors, thoughts and feelings in real-time (eg, how are you doing right now?). The strength of ESM is the high ecological validity. Moment-to-moment assessments in real-world settings address the problem of recall bias [22,23]. The promise of ESM data for early identification of adolescents at risk for the development of psychopathology has been demonstrated in a research setting with adults [24] and adolescents [25]. Moreover, self-management may be enhanced by obtaining insights into everyday functioning dynamics, based on ESM data [eg, 22,26,27].

The first choice of treatment of anxiety and mood problems in adolescents is psychological therapy, 
especially cognitive behaviour therapy (CBT) [28-30]. It is known that the way adolescents cope with stress or handle negative emotions in daily life may increase or buffer against the development of anxiety and depressive symptoms [31-33]. That is why CBT is one of the effective interventions aimed at improving coping. Recently, results of an internet-based CBT intervention revealed that positive effects occur already after 4 weeks CBT [34]. CBT is mostly used in clinical practice but increasingly also applied for preventive purposes [28,29].

Therefore, we co-created the Grow It! app (Android/iOS) for adolescents aged 12-25 years old. Grow It! is a multiplayer serious game, a game that is designed for a primary purpose other than entertainment [30]. Incorporated in the Grow It! app are ESM, to enhance self-management and identify mood problems earlier on, and gamified CBT-based challenges to increase coping. Initially, the app was developed for high-risk adolescent populations, such as adolescents with chronic somatic conditions, offspring of parents with psychiatric disorders, or adolescents experiencing extreme stressful societal circumstances, for example, the COVID-19 pandemic. However, the app may also serve a broader purpose of prevention for adolescents from a general population.

\section{Objectives}

The first aim of the current study is to give an elaborate description of the developmental process of the multiplayer serious game app Grow It!. Secondly, we aimed to study the feasibility and acceptance of Grow It! among end-users. 


\section{Methods}

\section{Developmental process}

The Grow It! app was developed, with intermittent periods, from March 2016 until February 2020 (Figure 1). During its development, we co-created the app with a large multi-disciplinary team of child and adolescent psychiatrists, developmental and clinical psychologists, data-analysts, game designers, and multiple test panels (adolescents from 12-25 years old) [35,36]. The initial concept was developed together with HKU University of the Arts (test 1a-1b). Then, with IJsfontein B.V. and consultancy company Game Architect Studio, an agile process (defined as: a software development methodology including iterative development, where requirements and solutions evolve in multidisciplinary teams [37]) was used to develop and evaluate the MVP (minimal viable product; test 2a-2e). For all tests informed consent was obtained.

\section{Initial concept}

In March 2016, the developmental process of Grow It! started with a pre-pilot (test 1a, $N=10$ ), which resulted in a paper-based prototype and wireframes. Later on, in the pilot (test 1b) adolescents from the general population ( $\mathrm{N}=21)$ tested the app’s beta-version during a 6-week trial. Week 1 and 6 of the test consisted of an ESM only study with eight mood-assessments per day. During weeks 2 to 5, the mood-assessments were given twice a day and combined with CBT-based challenges. In all weeks, users received feedback through push messages complimenting them. Lessons learned were that adolescents were motivated by the game mechanics of Grow It! and liked completing the ESM questionnaires and daily challenges.

\section{Minimal viable product}

In June 2019, the minimal viable product (MVP) was built. We aimed to improve the app's content, visual design, interaction design, reliability of assessments, and ran a technical test. The app was developed using agile development and user-centered design methods, including different tests and collaboration with focus groups. Different groups of adolescents $(\mathrm{N}=6, \mathrm{~N}=9)$ received instructions and were invited to design CBT-based challenges aiming at adaptive coping [36]. Thereafter, all ideas were formulated into specific challenges and were rated in terms of their clinical appropriateness and coping effectiveness by eleven child and youth psychologists and psychiatrists. As a result of these focus groups (test 2a) 126 challenges were formulated which were later used as the challenges in the Grow It! app. Furthermore, a survey among 107 adolescents (test 2b) resulted in the choice for a visual design that 1) was accepted by a broad range of ages and both by boys and girls, and 2) was low cost in maintenance. In interviews ( $\mathrm{N}=4$, test $2 \mathrm{c})$ with regard to the navigation 
of the app, special attention was given to the answer-scale development (Likert, VAS) to increase the assessments' reliability. In empirical studies on ESM data [22], VAS scales had demonstrated the anchor influenced results, and therefore different approaches were tested (eg, add a cursor above the anchor line). Interviews with adolescent indicated that Likert scales are more intuitive if they run from high to low on the screen instead of low to high. In December 2019 and February 2020, user experience tests of the Grow It! app were run (test 2d). Adolescents ( $\mathrm{N}=23$ ) played the Grow It! app for 1 week. Based on interviews, we improved and extended the content of the app by 1) adding a limited chat function with predesigned stickers to motivate team members, 2) allowing users to choose from 3 challenges a day for six weeks, and 3) adding a tour in which game mechanics are explained. Finally, a handbook for errors arose from our technical test and quality assessment which was performed by the research team $(\mathrm{N}=10$; test $2 \mathrm{e})$.

\section{Feasibility and acceptance test}

In May 2020 and in December 2020, at the first two peaks of the COVID-19 pandemic, the Grow It! app was launched to assess the game-mechanics and user acceptance of the MVP. Due to government restrictions, all adolescents had to follow social distancing measures (eg, staying at home because schools were closed). Through (social) media the app was made available to Dutch-speaking adolescents living in the Netherlands, aged 12-25, who owned a smartphone. Participants were consecutively enrolled in a Grow It! team after completion of the baseline questionnaire that was linked to the online informed consent procedure on a secure website. This way participants started with the app as soon as possible.

In total, 685 adolescents (sample 1: mean age 16.19, SD=3.11, 28.2\% boys) played the Grow It! app for six weeks, and in the second sample another 1035 adolescents (sample 2: mean age 18.78, $\mathrm{SD}=3.51,18.7 \%$ boys) played the Grow It! app for 3 weeks. A follow-up questionnaire was filled out by 383 and 644 adolescents for sample 1 and 2 respectively (see Table 1 for demographics). In the Grow It! app, participants were given five ESM notifications per day and daily challenges. Users who did not show activity in the app (0 or 1 activity in ESM/challenges) were excluded from the sample, because in order to evaluate the user experience of the Grow It! app we were interested in participants who were involved in playing the app.

A complete overview of all (ESM) instruments and questionnaires is published in our online codebook (https://osf.io/2at58/?view_only=b691104ecc3d45ad8b48e1bd60ad7125).

The outcomes of our feasibility and acceptance test can be found under the results section. Statistical analyses are descriptive (means, SDs, frequencies) and performed using SPSS (version 25; IBM 
Corp) [38].

Table 1. Sample characteristics and demographics

\begin{tabular}{|c|c|c|c|c|}
\hline & \multicolumn{2}{|c|}{ Sample 1} & \multicolumn{2}{|c|}{ Sample 2} \\
\hline & $\begin{array}{c}\text { App engagement } \\
\text { (Grow It! activity) } \\
\text { N=685 }\end{array}$ & $\begin{array}{c}\text { Follow-up } \\
\text { questionnaire } \mathrm{N}=383 \\
\text { (55.9\% retention) }\end{array}$ & $\begin{array}{l}\text { App engagement } \\
\text { (Grow It! activity) } \\
\text { N=1035 }\end{array}$ & $\begin{array}{c}\text { Follow-up } \\
\text { questionnaire } \mathrm{N}=644 \\
(62.2 \% \text { retention) }\end{array}$ \\
\hline Age & 16.19 (3.11) & $16.26(3.07)$ & $18.78(3.51)$ & $18.48(3.43)$ \\
\hline Gender \%boys & $28.2 \%$ & $26.0 \%$ & $18.6 \%$ & $18.7 \%$ \\
\hline Education levela & $\begin{array}{l}4.4 \% \text { primary school } \\
15.2 \% \text { low } \\
22.1 \% \text { medium } \\
58.2 \% \text { high }\end{array}$ & $\begin{array}{c}2.3 \% \text { primary school } \\
14.1 \% \text { low } \\
\text { 24.1\% medium } \\
59.5 \% \text { high }\end{array}$ & $\begin{array}{c}\text { 0.9\% primary school } \\
16.1 \% \text { low } \\
32.5 \% \text { medium } \\
42.3 \% \text { high } \\
8.1 \% \text { other }\end{array}$ & $\begin{array}{c}1.0 \% \text { primary school } \\
15.2 \% \text { low } \\
31.2 \% \text { medium } \\
\text { 45.5\% high } \\
7.1 \% \text { other }\end{array}$ \\
\hline $\begin{array}{l}\text { Cultural } \\
\text { identity }\end{array}$ & $\begin{array}{l}90.8 \% \text { Dutch } \\
8.3 \% \text { mixed } \\
0.9 \% \text { other }\end{array}$ & $\begin{array}{l}90.7 \% \text { Dutch } \\
1.1 \% \text { mixed } \\
8.1 \% \text { other }\end{array}$ & $\begin{array}{c}97.9 \% \text { Dutch } \\
1.6 \% \text { mixed } \\
0.5 \% \text { other }\end{array}$ & $\begin{array}{c}98.1 \% \text { Dutch } \\
1.7 \% \text { mixed } \\
0.3 \% \text { other }\end{array}$ \\
\hline
\end{tabular}

Note. ${ }^{\text {ap.s. }}=$ primary school, low $=$ (preparatory school for) technical and vocational training, middle = (preparatory school for) professional education, high = (preparatory school for) university.

\section{End-product of developmental process: the Grow It! app}

\section{User Journey}

The user journey first entails a phase of enrolment, during which participants can personalize their account. After receiving a six-digit code (letters and numbers) from the research team via text message, they log into Grow It! and choose their nickname based on two turntables. The first turntable shows an adjective (eg Adorable, Dangerous, Lucky, Creative Romantic) and the second turntable shows an animal name (eg Alpaca, Snake, Iguana, Rabbit, Crocodile). Participants can rotate the turntables as often as they want to personalize their nickname. For example, one participant nickname could be Lucky Rabbit or Adorable Alpaca (Figure 2). The game mechanics (ie, personalization, collaboration, competition, and feedback) are explained in the mandatory tour of the Grow It! app.

\section{Collaboration}

As adolescents are sensitive to peer influence and can be motivated by interactions with peers [3941], each participant collaborates anonymously in a team with 3-7 other players. Adolescents are allocated to a team by the researchers. To support team members, participants can chat by sending and receiving positive stickers (Figure 3). Via this chat system, participants can motivate each other, 
while the system minimizes the possibilities of bullying and negative peer pressure.

\section{Competition}

Competition is encouraged at the team level, where teams play versus each other. Each team has a virtual tree with a name (eg, the Oaks, the Pines, the Palms), which allows participants to compare their team performance to other teams (Figure 4). At the start of the game, the tree is empty. Teams "grow" their tree when participants receive points by reporting their feelings and behaviours (ESM) and doing daily challenges. These reports are personal and shielded. Team members only see the amount of points their teammates have collected. After a team collects a specified amount of points, they achieve a "spurt" (ie, level-up), which means that the tree grows in height, and every team member receives a gift to embellish the tree (Figure 5 and 6). As game mechanics, these provide a positive feedback loop, a progress update, and establish the reward scheme or the behavioural conditioning that increases retention. Upon earning a gift (ie, loot box) from a growth spurt, a participant can then select his/her choice from three gifts. The gifts are wrapped so that there is no indication of what is inside. As a game mechanic, selecting a random gift creates surprise and moments of anticipation essential to maintaining a state-of-play [42]. When teams have just started using the app, it does not take many points to achieve the first "spurt" and earn a gift. As the game progresses, however, and teams move to higher levels, more and more points are needed to earn a "spurt" and gifts. In this way, adolescents are stimulated to keep playing and remain engaged with the app. The difficulty level is scaffolded by incrementally increasing difficulty, which supports retention by continuously challenging the participants as they progress through the game.

\section{Feedlback}

The game mechanics of Grow It! provide feedback at different levels. Whereas users can see their own and their team members' scores in the score overview screen (Figure 7), on their profile page they obtain an overview of how many times they reported their feelings, behaviours, and challenges that day (Figure 8). Finally, the Grow It! app has a contact button in case of technical issues or urgent psychological problems. Whenever a participant pushes the contact button, a phone number is displayed through which the research team can be reached by telephone or text on working days during office hours. On the study website information can be found on how to reach help in acute situations or outside working hours, referring to professional and free services.

\section{Daily emotions}

ESM is an integral part of the app which can be used for early identification of emotional problems and enhancing self-management in adolescents [22]. To prompt adolescents to report on their 
feelings, they receive several notifications per day, which are randomized to prevent structural answering patterns (eg, always in math class at 11:00 AM) [22]. In the first studies, adolescents answered five micro-questionnaires per day (taking approx. 1-2 minutes) regarding their sleep, activity, affective well-being (eg, I feel happy or sad), coping strategies, pain, fatigue, social behaviour, loneliness, stress and coping (Figure 9).

Our ESM approach's novelty is that it is gamified to increase motivation, which intends to result in a higher rate of compliance (percentage completed self-evaluations) as well as improved data quality [eg, 15]. Compliance is one of the critical quality markers for ESM studies [22].

\section{Daily challenges}

To teach adolescents how to cope with setbacks and to promote emotional resilience, the Grow It! app contains daily challenges aimed at strengthening adaptive coping, supporting physical activation and preventing emotional problems. Coping styles incorporated in the challenges promote distraction, problem-solving, social support, and acceptance [43,44]. Participants can choose one out of three challenges per day (Figure 10). Challenges are divided into three categories: photo challenges, quizzes and assignments. Examples of challenges are: make a picture of something you hold dear (photo challenge; aimed at distraction), ask someone what they like about you and write it down (assignment; aimed at social support), or answer a multiple-choice question like 'What is sushi usually rolled in?' (quiz; aimed at problem solving). An additional, randomly available assignment is the photo check. Participants are shown a matrix of nine photos and assess which photos fit a particular theme. In this way, they act as the photo challenge jury and can award points to participants and earn extra points themselves for this task.

\section{Ethical Considerations and Privacy}

Risks related to privacy were mitigated by making all participants pseudonymous and only identifiable in the app by participation codes and pseudonyms. Participants determine their pseudonym (ie, nickname) from a pre-selected set of words provided by the app. Participants cannot be identified and only the research team has insight into the private data of the participants. Data collected with the app pertains to the user's game data (eg game-specific actions) and responses to the ESM. The app also accesses the mobile device's camera, but only when a participant takes a photo for a challenge (not at other times), and the app does not access other functionalities (eg, google, GPS, health apps). All user data is encrypted and sent directly to a secure server at the 
researcher's institute. The privacy and security of the Grow It! app is approved by the privacy and security office of Erasmus MC, and the app complies with the Dutch General Data Protection Regulation (AVG) and NEN-norm 7510:2017 (Dutch standard of information security management systems in healthcare). The app is currently available for research purposes in the Google Play store (https://play.google.com/store/apps/details?id=nl.erasmusmc.growit) and Apple store (https://apps.apple.com/nl/app/grow-it/id1496767455). This study has been approved by the Medical Ethics Committee of the Erasmus Medical Center (MEC-2020-0287).

\section{Results}

As shown in Table 1, participants of sample $1\left(\mathrm{~N}=685, \mathrm{M}_{\mathrm{age}}=16.2, \mathrm{SD}=3.1\right)$ were somewhat younger compared to adolescents in sample $2\left(\mathrm{~N}=1035, \mathrm{M}_{\text {age }}=18.8\right.$, $\mathrm{SD}=3.5)$. In general, participants of both samples were relatively high educated and mostly of Dutch ethnicity. The follow-up questionnaire was filled out by $55.9 \%$ and $62.2 \%$ of the users in sample 1 and sample 2 respectively.

\section{Feasibility and Acceptance}

An overview of app engagement (ESM compliance and challenges) and answers of the user evaluation questionnaire carried out in the follow-up can be found in Table 2 and 3.

Regarding the ESM component, overall compliance was 16.7\% (sample 1) and 30.9\% (sample 2). About 56\% of the participants indicated that they thought the number of questions per day was too much, while about $40 \%$ indicated the number of questions as sufficient. Some participants also reported that they did not understand why the same questions were asked repeatedly (Sample 1: $\mathrm{N}=20$, Sample $2 \mathrm{~N}=16$; ie, at each notification, the same ESM questions were asked to monitor their feelings and behaviour over the study weeks). Fifteen to $22.9 \%$ reported no effect of the ESM. However, 66.8-72.4\% reported reflecting more on their feelings as a result of the ESM.

With regard to the daily CBT-based challenges, participants completed 31.5-49.5\% of all challenges. While in sample 1 eight participants completed all 42 challenges (100\%), 68 participants completed all 21 challenges (100\%) in sample 2. The self-reported effect of the challenges showed that 20.7$44.2 \%$ of the participants became more active as a result of the Grow It! challenges.

The overall user evaluation of Grow It! was positive. The average app evaluation score was 7.1 out of $10(\mathrm{SD}=1.5)$ in sample 1 and 7.2 out of $10(\mathrm{SD}=1.3)$ in sample 2. Moreover, the app's design was evaluated with a 7.7-8.0 out of 10. Finally, 72.6-75.6\% would recommend the app to their friends. 


\section{Results for adolescents compared to emerging adults}

Given the broad age range in which adolescents participated (12-25 years) we also reported outcomes separately for adolescents (12-17 years) and emerging adults (18-25 years) in Table 2 and 3. Higher user evaluations of the Grow It! app were found in the adolescent group in comparison to the emerging adult group (ie, sample 1 and 2: adolescents rated the design of the app higher, more adolescents would recommend the app to their friends in 1-2, sample 1: adolescents' evaluation of the app was higher, number of ESM notifications per day was evaluated better, sample 2: evaluation of the chat function was better in adolescents). Moreover, no differences between age groups were found with regard to app engagement with the exception of slightly higher compliance of ESM in emerging adults compared to adolescents (only in sample 1). 
Table 2. App engagement and user evaluation of Grow It! (Sample 1)

\begin{tabular}{|c|c|c|c|c|}
\hline & Total & Aged 12-17 & Aged 18-25 & Difference test \\
\hline \multicolumn{5}{|l|}{$\begin{array}{l}\text { p engagement (Grow It! } \\
\text { ivity) }\end{array}$} \\
\hline & $\mathrm{N}=685$ & $\mathrm{~N}=500$ & $\mathrm{~N}=185$ & $12-17$ vs. $18-25$ \\
\hline ompliance ESM (\%) & $16.7 \%(21.1)$ & $16.4(20.6)$ & $19.9(23.1)$ & $\begin{array}{c}\mathrm{t}(683) 1.89 \\
p=0.06\end{array}$ \\
\hline hallenges (\%) & $31.5 \%(26.7)$ & $31.6(26.3)$ & $31.2(27.8)$ & $\begin{array}{l}\mathrm{t}(683) 0.19 \\
\quad p=0.85\end{array}$ \\
\hline \multicolumn{5}{|l|}{$\begin{array}{l}\text { er evaluation (follow-up } \\
\text { estionnaire) }\end{array}$} \\
\hline & $\mathrm{N}=383$ & $\mathrm{~N}=273$ & $\mathrm{~N}=110$ & \\
\hline valuation of the app (1-10) & $7.1(1.5)$ & $7.4(1.3)$ & $6.6(1.7)$ & $\mathrm{t}(381) 4.70^{* *}$ \\
\hline $\begin{array}{l}\text { valuation of the design (1- } \\
\text { 0) }\end{array}$ & $7.7(1.5)$ & $7.8(1.5)$ & $7.5(1.5)$ & $\mathrm{t}(381) 2.21^{*}$ \\
\hline elf-reported effect ESM & $\begin{array}{c}\text { 5.3\% I got to know myself } \\
\text { better } \\
5.0 \% \text { It made me feel } \\
\text { better } \\
\text { 66.8\% It made me think } \\
\text { about how I feel more } \\
22.9 \% \text { No effect }\end{array}$ & $\begin{array}{c}\text { 6.3\% I got to know myself } \\
\text { better } \\
\text { 4.7\% It made me feel } \\
\text { better } \\
\text { 66.4\% It made me think } \\
\text { about how I feel more } \\
22.5 \% \text { No effect }\end{array}$ & $\begin{array}{c}2.9 \% \text { I got to know myself } \\
\text { better } \\
5.7 \% \text { It made me feel } \\
\text { better } \\
67.6 \% \text { It made me think } \\
\text { about how I feel more } \\
23.8 \% \text { No effect }\end{array}$ & $\chi^{2} 1.99 p=0.58$ \\
\hline $\begin{array}{l}\text { valuation amount of ESM } \\
\text { er day }\end{array}$ & $\begin{array}{c}\text { 4.0\% few } \\
40.3 \% \text { sufficient } \\
55.7 \% \text { a lot }\end{array}$ & $\begin{array}{c}3.0 \% \text { few } \\
44.8 \% \text { sufficient } \\
52.2 \% \text { a lot }\end{array}$ & $\begin{array}{c}6.5 \% \text { few } \\
29.0 \% \text { sufficient } \\
64.5 \% \text { a lot }\end{array}$ & $x^{2} 9.18^{* *}$ \\
\hline $\begin{array}{l}\text { elf-reported effect of } \\
\text { hallenges }\end{array}$ & $\begin{array}{c}\text { 2.5\% I have had more } \\
\text { contact with others } \\
\text { 2.2\% I am better at solving } \\
\text { problems } \\
\text { 8.3\% I am better at } \\
\text { accepting situations } \\
20.7 \% \text { I have become } \\
\text { more active } \\
\text { 7.4\% I have started to feel } \\
\text { less lonely }\end{array}$ & $\begin{array}{c}\text { 2.3\% I have had more } \\
\text { contact with others } \\
\text { 1.5\% I am better at solving } \\
\text { problems } \\
\text { 8.1\% I am better at } \\
\text { accepting situations } \\
\text { 23.6\% I have become } \\
\text { more active } \\
\text { 7.3\% I have started to feel } \\
\text { less lonely }\end{array}$ & $\begin{array}{c}\text { 2.9\% I have had more } \\
\text { contact with others } \\
\text { 3.8\% I am better at solving } \\
\text { problems } \\
\text { 8.7\% I am better at } \\
\text { accepting situations } \\
\text { 13.5\% I have become } \\
\text { more active } \\
\text { 7.7\% I have started to feel } \\
\text { less lonely }\end{array}$ & $\chi^{2} 5.26 p=0.26$ \\
\hline valuation chat function & $\begin{array}{c}20.7 \% \text { not nice at all } \\
45.7 \% \text { a little bit nice } \\
14.1 \% \text { quite nice } \\
11.7 \% \text { nice } \\
\text { 7.9\% very nice }\end{array}$ & $\begin{array}{c}\text { 18.7\% not nice at all } \\
44.7 \% \text { a little bit nice } \\
14.9 \% \text { quite nice } \\
12.2 \% \text { nice } \\
\text { 9.5\% very nice }\end{array}$ & $\begin{array}{c}25.5 \% \text { not nice at all } \\
48.1 \% \text { a little bit nice } \\
13.3 \% \text { quite nice } \\
10.4 \% \text { nice } \\
\text { 3.8\% very nice }\end{array}$ & $\chi^{2} 5.79 p=0.22$ \\
\hline $\begin{array}{l}\text { o would recommend Grow } \\
\text { ! to friends }\end{array}$ & $72.6 \%$ & $77.7 \%$ & $60.0 \%$ & $x^{2} 12.28^{* *}$ \\
\hline $\begin{array}{l}\text { o want to help with future } \\
\text { evelopment of the app }\end{array}$ & $34.7 \%$ & $33.9 \%$ & $36.9 \%$ & $\chi^{2} 0.35 p=0.55$ \\
\hline
\end{tabular}

$* * \mathrm{p}<0.01 * \mathrm{p}<0.05$

Table 3. App engagement and user evaluation of Grow It! (Sample 2) 


\begin{tabular}{|c|c|c|c|c|}
\hline $\begin{array}{l}\text { p engagement (Grow It! } \\
\text { tivity) }\end{array}$ & & & & \\
\hline & $\mathrm{N}=1035$ & $\mathrm{~N}=405$ & $\mathrm{~N}=630$ & \\
\hline ompliance ESM (\%) & $30.9(26.6)$ & $28.6(25.4)$ & $32.3(27.3)$ & $t(1033) 2.17^{*}$ \\
\hline hallenges (\%) & 49.5 (29.9) & $50.1(29.4)$ & $49.2(30.2)$ & $\begin{array}{c}t(1033) 0.45 \\
\quad p=0.65\end{array}$ \\
\hline \multicolumn{5}{|l|}{$\begin{array}{l}\text { er evaluation (follow-up } \\
\text { estionnaire) }\end{array}$} \\
\hline & $\mathrm{N}=644$ & $\mathrm{~N}=256$ & $\mathrm{~N}=388$ & \\
\hline valuation of the app (1-10) & $7.2(1.3)$ & $7.5(1.3)$ & $6.9(1.3)$ & $\begin{array}{c}t(642) 1.59 \\
p=0.11\end{array}$ \\
\hline $\begin{array}{l}\text { valuation of the design (1- } \\
\text { 0) }\end{array}$ & $8.0(1.3)$ & $8.2(1.3)$ & $7.8(1.3)$ & $t(624) 4.48^{* *}$ \\
\hline elf-reported effect ESM & $\begin{array}{c}\text { 9.6\% I got to know myself } \\
\text { better } \\
12.5 \% \text { It made me feel } \\
\text { better } \\
\text { 72.4\% It made me think } \\
\text { about how I feel more } \\
15.0 \% \text { No effect }\end{array}$ & $\begin{array}{l}\text { 10.4\% I got to know } \\
\text { myself better } \\
\text { 5.2\% It made me feel } \\
\text { better } \\
\text { 68.0\% It made me think } \\
\text { about how I feel more } \\
\text { 16.4\% No effect }\end{array}$ & $\begin{array}{c}\text { 9.0\% I got to know myself } \\
\text { better } \\
\text { 1.5\% It made me feel } \\
\text { better } \\
\text { 75.3\% It made me think } \\
\text { about how I feel more } \\
14.2 \% \text { No effect }\end{array}$ & $x^{2} 8.54^{*}$ \\
\hline $\begin{array}{l}\text { valuation amount of ESM } \\
\text { er day }\end{array}$ & $\begin{array}{l}1.7 \% \text { few } \\
40.9 \% \text { sufficient } \\
57.4 \% \text { a lot }\end{array}$ & $\begin{array}{l}\text { 1.8\% few } \\
46.5 \% \text { sufficient } \\
51.6 \% \text { a lot }\end{array}$ & $\begin{array}{l}\text { 1.7\% few } \\
37.2 \% \text { sufficient } \\
61.2 \% \text { a lot }\end{array}$ & $\chi^{2} 5.77 p=0.06$ \\
\hline $\begin{array}{l}\text { elf-reported effect of } \\
\text { hallenges }\end{array}$ & $\begin{array}{c}\text { 16.5\% I have had more } \\
\text { contact with others } \\
\text { 4.5\% I am better at solving } \\
\text { problems } \\
\text { 18.7\% I am better at } \\
\text { accepting situations } \\
\text { 44.2\% I have become } \\
\text { more active } \\
\text { 16.1\% I have started to } \\
\text { feel less lonely }\end{array}$ & $\begin{array}{c}\text { 12.0\% I have had more } \\
\text { contact with others } \\
\text { 6.3\% I am better at solving } \\
\text { problems } \\
\text { 18.3\% I am better at } \\
\text { accepting situations } \\
\text { 47.2\% I have become } \\
\text { more active } \\
\text { 16.2\% I have started to } \\
\text { feel less lonely }\end{array}$ & $\begin{array}{l}\text { 20.0\% I have had more } \\
\text { contact with others } \\
\text { 3.0\% I am better at solving } \\
\text { problems } \\
\text { 19.0\% I am better at } \\
\text { accepting situations } \\
\text { 41.7\% I have become } \\
\text { more active } \\
\text { 16.1\% I have started to } \\
\text { feel less lonely }\end{array}$ & $x^{2} 10.47^{*}$ \\
\hline valuation chat function & $\begin{array}{c}22.0 \% \text { not nice at all } \\
44.7 \% \text { a little bit nice } \\
16.4 \% \text { quite nice } \\
12.0 \% \text { nice } \\
4.9 \% \text { very nice }\end{array}$ & $\begin{array}{c}\text { 13.5\% not nice at all } \\
\text { 42.7\% a little bit nice } \\
21.2 \% \text { quite nice } \\
16.1 \% \text { nice } \\
6.6 \% \text { very nice }\end{array}$ & $\begin{array}{c}27.6 \% \text { not nice at all } \\
46.0 \% \text { a little bit nice } \\
13.2 \% \text { quite nice } \\
9.4 \% \text { nice } \\
\text { 3.8\% very nice }\end{array}$ & $\chi^{2} 28.11^{* *}$ \\
\hline $\begin{array}{l}\text { o would recommend Grow } \\
\text { ! to friends }\end{array}$ & $75.6 \%$ & $84.0 \%$ & $70.0 \%$ & $x^{2} 16.12^{* *}$ \\
\hline $\begin{array}{l}\text { o want to help with future } \\
\text { evelopment of the app }\end{array}$ & $40.9 \%$ & $45.7 \%$ & $37.7 \%$ & $x^{2} 0.74 p=0.39$ \\
\hline
\end{tabular}

$$
{ }^{* * *} p<0.01{ }^{*} p<0.05
$$




\section{Discussion}

\section{Principal Findings}

The Grow It! app emerged from a lack of and need for preventive interventions for emotional problems and promoting adaptive coping for adolescents_additionally, these interventions needed to be low-key, non-stigmatizing, fun, attractive, private and secure. Based on the developmental process and acceptance and feasibility of Grow It! key lessons learned and directions for future research are formulated and shared. Our approach entails an iterative game design process combined with an agile method to develop the smartphone app. The incorporated game features in the Grow It! app were co-designed with adolescent end-users to increase participant engagement and adherence. With regard to the app engagement and user evaluation filled out at follow-up we indicated that we have some evidence that supports the feasibility and acceptance, and therefore applicability, of Grow It! in adolescents.

Earlier studies suggest that adolescents are open to using mHealth [45]. Indeed, the large interest as well as the positive user evaluation provide reason to believe that adolescents, at least a large group, are positive and open to using mHealth. Grow it was co-designed with youth, which was reflected in age adequate daily challenges and an overall positive rating of the Grow It! app. Sixty-seven to $72.4 \%$ of the participants felt they reflected more on their emotions.

\section{Limitations}

Although the results of the developmental process, acceptance and feasibility are informative and promising for mHealth, several limitations should be mentioned. First, the majority of the study sample consisted of girls. The design of the app seems more appealing to girls, despite the long process of co-creation with both boys and girls. One of the explanations might be that girls are more inclined to seek help [46] and therefore are also more inclined to participate in our study.

Second, the COVID-19 pandemic and related governmental restrictions might have influenced the results. Due to remote working during the COVID-19 pandemic, participants had no or minimal personal contact and received minimal instructions on how to participate in an ESM study, while this is stated as an important factor to obtain reliable data [22]. Third, concerning self-monitoring, it is notoriously difficult to motivate adolescents. In this study, compliance of ESM was lower than in a typical research design [22], however participants received no financial incentive and were entirely motivated by the game structure to answer questionnaires. We, therefore, expect that with more targeted use (eg, in blended care when the app is explained by a professional), the compliance and 
user satisfaction might be more favourable. Furthermore, dropout rates were comparable to other online studies [47]. In order to increase app engagement, improvements are needed, for instance, designs may need to be tailored to the individual (personalization) and (in person) feedback is needed.

\section{Future directions}

With regard to the early identification of emotional problems, ESM data of the Grow It! app provides an opportunity to develop algorithms in future research for the early detection of emotional problems, which often go unnoticed in adolescents [6]. Identifying emotional problems early on would require capitalizing on novel developments in clinical psychology [48] combined with the motivational game architecture co-developed with youth [36]. ESM has already shown to be a reliable method to investigate variation in thoughts, feelings and symptoms over time and context in research settings [22,23]. Recently Dietvorst et al. [25], have demonstrated that ESM data helps to identify the onset of depressive feelings among adolescents 3 months ahead. Specifically, this was done by differentiating typical adolescents (eg, grumpy at home), from early depressive feelings. In future work, analyzing highly rich ESM data with more powerful analytical techniques, such as machine learning, could potentially improve this early identification.

In clinical practice, self-management and self-insight may be enhanced by obtaining insights into one's emotion dynamics [eg 22,26,27]. A feature such as providing participants with feedback through a daily life emotion chart (eg, mood profile) could provide participants with better insight and feedback into their well-being [49,50]. It may also serve as a therapeutic function, as integrating real-time mood profiles in the app could encourage adolescents to reflect more on their emotions, coping and behaviour in different contexts [26], and could also be used as a routine outcome measure during therapy. To test the effects of the app upon adolescent well-being and resilience an additional in-depth evaluation is required. Research questions and hypotheses that are beyond the scope of the developmental process focusing on the main effect of the app are preregistered [51, 52] and will be executed in the future accordingly, including a randomized controlled trial (RCT) study to test the effectiveness of the Grow It! app.

\section{Conclusion}

The Grow It! app has been developed and improved through iterations in collaboration with a large multi-disciplinary team. It is innovative, age-attuned, easily accessible, fun, visually appealing and most importantly, serves the needs of adolescents. The app was well received by adolescents and the 
first findings presented here indicate that adolescents were motivated by the game mechanics of Grow It! and liked completing the ESM questionnaires and daily challenges. Initially, the app was developed for high-risk adolescent populations, such as adolescents with chronic somatic conditions, offspring of parents with psychiatric disorders, or adolescents experiencing extreme stressful societal circumstances, for example, the COVID-19 pandemic. However, the app may also serve a broader purpose of prevention for adolescents from a general population. Our findings support the feasibility and acceptance, and therefore applicability, of the Grow It! app in adolescents.

The ambition is to further improve the app after each research study by including new features and resolving usability issues. The next step will be to focus on the increase of compliance and providing participants feedback through their personal mood profiles. 


\section{Acknowledgments}

This research is funded by Netherlands Organization for Health Research and Development 'Juiste Zorg Op De Juiste Plek' (ZonMw JZOJP) together with the Netherlands Organisation for Scientific Research (NWO; project number: 440.20.006), the Stichting Vrienden van het Sophia (SSWO; project number: B18-05), Gemeente Rotterdam (project numbers: SUB.20.03.00149.SBSA and 40258362) and the Dutch National Research Agenda (NWA/eHealth Junior consortium; project number: 1292.19.226).

\section{Conflicts of Interest}

None declared.

\section{Abbreviations}

CBT: cognitive behavioural therapy

ESM: Experience Sampling Method mHealth: mobile health

MVP: minimal viable product

RCT: randomized controlled trial 


\section{References}

1. Thapar A, Collishaw S, Pine DS, Thapar AK. Depression in adolescence. Lancet (London, England) 2012;379(9820):1056-67. [doi: 10.1016/S0140-6736(11)60871-4]

2. Cummings CM, Caporino NE, Kendall PC. Comorbidity of anxiety and depression in children and adolescents: 20 years after. Psychol Bull. 2014;140(3):816.

[doi: 10.1037/a0034733]

3. World Health Organization (WHO). 2019. Adolescent mental health [Fact sheet]. https://www.who.int/news-room/fact-sheets/detail/adolescent-mental-health.

4. Garber J, Keiley MK, Martin NC. Developmental trajectories of adolescents' depressive symptoms: predictors of change. J Consult Clin Psychol. 2002;70(1):79-95. [doi: 10.1037/0022-006X.70.1.79]

5. Ormel J, Raven D, Van Oort F, Hartman CA, Reijneveld SA, Veenstra R, et al. Mental health in Dutch adolescents: a TRAILS report on prevalence, severity, age of onset, continuity and co-morbidity of DSM disorders. Psychol Med. 2015;45(2):345-360. [doi: 10.1017/S0033291714001469]

6. Kessler RC, Angermeyer M, Anthony JC, et al. Lifetime prevalence and age-of-onset distributions of mental disorders in the World Health Organization's World Mental Health Survey Initiative. World Psychiatry. 2007 Oct;6(3):168-176. [Medline: 18188442]

7. Leijdesdorff SMJ, Huijs CEM, Klaassen RMC, Popma A, van Amelsvoort TAMJ, Evers SMAA. Burden of mental health problems: quality of life and cost-of-illness in youth consulting Dutch walk-in youth health centres. J Ment Health. 2020;22:1-8. [doi: 10.1080/09638237.2020.1836555]

8. Raven D, Jörg F, Visser E, Oldehinkel AJ, Schoevers RA. Time-to-treatment of mental disorders in a community sample of Dutch adolescents. A TRAILS study. Epidemiol Psychiatr Sci. 2017;26(2):177. [doi: 10.1017/S2045796016000226]

9. Eijlers R, Legerstee JS, Dierckx B et al. Development of a virtual reality exposure tool as psychological preparation for elective pediatric day care surgery: methodological approach for a randomized controlled trial. JMIR Res Protoc. 2017;6(9):e174.[doi: 10.2196/resprot.7617]

10. Granic I, Lobel A, Engels RC. The benefits of playing video games. Am Psychol. 2014;69(1):66. [doi: 10.1037/a0034857]

11. Watts SE, Andrews G. Internet access is NOT restricted globally to high income countries: so why are evidenced based prevention and treatment programs for mental disorders so rare? Asian J Psychiatr. 2014;10:71-4. [doi: 10.1016/j.ajp.2014.06.007]

12. Schröder J, Berger T, Westermann S, Klein JP, Moritz S. Internet interventions for depression: new developments. Dialogues Clin Neurosci. 2016;18(2):203-212. [doi: 10.31887/DCNS.2016.18.2/jschroeder]

13. Ehrmann J, Lewis C, Lewis P. Homo ludens revisited. Yale Fr Stud. 1968;(41):31-57. [doi: $10.2307 / 2929664]$

14. Lieberman, D. A. (2006). What can we learn from playing interactive games. Playing video games: Motives, responses, and consequences, 379-397.

15. Van Berkel N, Goncalves J, Hosio S, Kostakos V. Gamification of mobile experience sampling improves data quality and quantity. Proceedings of the ACM on Interactive, Mobile, Wearable and Ubiquitous Technologies [Internet]. Association for Computing Machinery (ACM); 2017 Sep 11;1(3):1-21. [doi.org/10.1145/3130972]

16. Brown S, Vaughan C. Play: How it shapes your brain, opens the imagination, and invigorates the soul. Penguin; 2010.

17. McGonigal J. Reality is broken: Why games make us better and how they can change the 
world. Penguin; 2011.

18. Visch VT, Vegt NJH, Anderiesen H, Van der Kooij K. Persuasive game design: A model and its definitions. Paper presented in CHI 2013 Workshop on Designing Gamification: Creating Gameful and Playful Experiences. Paris, France; 2013.

19. Keijsers L, Van Roekel E. Longitudinal methods in adolescent psychology: Where could we go from here? And should we? In: Kloep LBHM, ed. Reframing adolescent research. London/Routledge; 2018:70-91.

20. Proudfoot J, Parker G, Hadzi Pavlovic D, Manicavasagar V, Adler E, Whitton A. Community attitudes to the appropriation of mobile phones for monitoring and managing depression, anxiety, and stress. J Med Internet Res. 2010;12:e64. [doi: 10.2196/jmir.1475]

21. Gindidis S, Stewart S, Roodenburg J. A systematic scoping review of adolescent mental health treatment using mobile apps. Adv Ment Health. 2019;17(2):161-177. [doi: 10.1080/18387357.2018.1523680]

22. Van Roekel E, Keijsers L, Chung JM. A review of current ambulatory assessment studies in adolescent samples and practical recommendations. J Res Adolesc. 2019;29(3):560-577. [doi: 10.1111/jora.12471]

23. Larson R, Csikszentmihalyi M. Chapter 2: The Experience Sampling Method. In: Csikszentmihalyi M. Flow and the Foundations of Positive Psychology. Springer Science+Business Media Dordrecht; 2014:21-34. [doi: 10.1007/978-94-017-9088-8_2]

24. Wichers M, Smit AC, Snippe E. Early warning signals based on momentary affect dynamics can expose nearby transitions in depression: A confirmatory single-subject time-series study. JPOR. 2020;v6(n1):1-15. [doi: 10.17505/jpor.2020.22042]

25. Dietvorst E, Hiemstra M, Maciejewski D, van Roekel E, Ter Bogt TFM, Hillegers MHJ, Keijsers L. Grumpy or depressed? Disentangling typically developing adolescent mood from prodromal depression using Experience Sampling Methods. J Adolesc. 2021;88:25-35. [doi: 10.1016/j.adolescence.2021.01.009]

26. Van Os J, Verhagen S, Marsman A, et al. The experience sampling method as an mHealth tool to support self-monitoring, self-insight, and personalized health care in clinical practice. Depress Anxiety. 2017;34(6):481-493. [doi: 10.1002/da.22647]

27. Widdershoven RLA, Wichers M, Kuppens P, et al. Effect of self-monitoring through experience sampling on emotion differentiation in depression. J Affect Disord. 2019;244:7177. [doi:10.1016/j.jad.2018.10.092]

28. Havinga PJ, Maciejewski DF, Hartman CA, Hillegers MHJ, Schoevers RA, Penninx BW. Prevention programmes for children of parents with a mood/anxiety disorder: Systematic review of existing programmes and meta-analysis of their efficacy. Br. J. Clin. Psychol. 2021. [doi:10.1111/bjc.12277]

29. National Collaborating Centre for Mental Health. The NICE guideline on the treatment and management of depression in adults. The British Psychological Society and The Royal College of Psychiatrists; 2010. ISBN:9781904671855

30. Djaouti, D., Alvarez, J., \& Jessel, J. P. (2011). Classifying serious games: the G/P/S model. In Handbook of research on improving learning and motivation through educational games: Multidisciplinary approaches (pp. 118-136). IGI Global.

31. Cohen S, Wills TA. Stress, social support, and the buffering hypothesis. Psychol Bull. 1985;98(2):310-357. [doi: 10.1037/0033-2909.98.2.310]

32. Cohen S. Social relationships and health. Am Psychol. 2004;59:676-684. [doi: 10.1037/0003066X.59.8.676]

33. Compas BE, Connor-Smith J, Jaser SS. Temperament, stress reactivity, and coping:implications for depression in childhood and adolescence. J Clin Child Adolesc Psychol. 2004;33(1):21-31. [doi: 10.1207/S15374424JCCP3301_3]

34. Fu, Z., Burger, H., Arjadi, R., Nauta, M. H., \& Bockting, C. L. H. (2021). Explaining the 
Efficacy of an Internet-Based Behavioral Activation Intervention for Major Depression: A Mechanistic Study of a Randomized-Controlled Trial. Clinical Psychology in Europe, 3(3), 124. https://doi.org/10.32872/cpe.5467

35. Eberle SG. The elements of play: Toward a philosophy and a definition of play. Am. J. Play. 2014;6(2):214-233.

36. Scholten H, Granic I. Use of the principles of design thinking to address limitations of digital mental health interventions for youth: Viewpoint. $\mathrm{J}$ Med Internet Res. 2019;21(1):e11528. [doi: 10.2196/11528]

37. Cohen, D., Lindvall, M., \& Costa, P. (2004). An introduction to agile methods. Adv. Comput., 62(03), 1-66.

38. IBM Corp. Released 2017. IBM SPSS Statistics for Windows, Version 25.0. Armonk, NY: IBM Corp

39. Radomski A, Wozney L, McGrath P, et al. A design and delivery features that may improve the use of internet-based cognitive behavioral therapy for children and adolescents with anxiety: A realist literature synthesis with a persuasive systems design perspective. J Med Internet Res. 2019;21(2):e11128. [doi:10.2196/11128]

40. Ryan AM. The peer group as a context for the development of young adolescent motivation and achievement. Child Dev. 2001;72(4):1135-1150. [doi: 10.1111/14678624.00338]

41. Van Hoorn J, van Dijk E, Meuwese R, Rieffe C, Crone EA. Peer influence on prosocial behavior in adolescence. J Res Adolesc. 2016;26:90-100. [doi:10.1111/jora.12173]

42. Telzer, EH, van Hoorn J, Rogers CR, Do KT. Social influence on positive youth development: A developmental neuroscience perspective. Adv Child Dev Behav. 2018;54:215-258. [doi: 10.1016/bs.acdb.2017.10.003]

43. Legerstee JS, Garnefski N, Jellesma FC, Verhulst FC, Utens EM. Cognitive coping and childhood anxiety disorders. Eur Child Adolesc Psychiatry. 2010;19(2):143-150. [doi: 10.1007/s00787-009-0051-6]

44. Connor-Smith JK, Compas BE, Wadsworth ME, Thomsen AH, Saltzman H. Responses to stress in adolescence: measurement of coping and involuntary stress responses. J Consult Clin Psychol. 2000;68(6):976-992. [doi: 10.1037/0022-006X.68.6.976]

45. Bergin, A. D., Vallejos, E. P., Davies, E. B., Daley, D., Ford, T., Harold, G., ... \& Hollis, C. (2020). Preventive digital mental health interventions for children and young people: a review of the design and reporting of research. NPJ digital medicine, 3(1), 1-9.

46. Marcell AV, Klein JD, Fischer I, Allan MJ, Kokotailo PK. Male adolescent use of health care services: Where are the boys? Journal of Adolescent Health. 2002;30(1):35-43. [doi:10.1016/ S1054-139X(01)00319-6]

47. Linardon, J., \& Fuller-Tyszkiewicz, M. (2020). Attrition and adherence in smartphonedelivered interventions for mental health problems: A systematic and meta-analytic review. Journal of consulting and clinical psychology, 88(1), 1.

48. Schreuder MJ, Hartman CA, George SV, Menne-Lothmann C, Decoster J, van Winkel R. Early warning signals in psychopathology: what do they tell?. BMC Med. 2020;18(1):1-11. [doi: 10.1186/s12916-020-01742-3]

49. Thabrew H, Fleming T, Hetrick S, Merry S. Co-design of eHealth interventions with children and young people. Front Psychiatry. 2018;9(481). [doi:10.3389/fpsyt.2018.00481]

50. Riese H, von Klipstein L, Schoevers RA, van der Veen DC, Servaas MN. Personalized ESM monitoring and feedback to support psychological treatment for depression: a pragmatic randomized controlled trial (Therap-i). BMC psychiatry. 2021;21(1):1-11. [doi:10.1186/s12888-021-03123-3]

51. Dietvorst et al. (preregistered). The Grow It! Serious Game Longitudinal Changes in 
Adolescent Well-being During COVID-19 (https://osf.io/2at58/? view_only=b691104ecc3d45ad8b48e1bd60ad7125)

52. Mens et al. (preregistered). Mapping Mood during the COVID-10 pandemic in Dutch Adolescents (https://osf.io/eu5vt/?view_only=3c6e7ce7f8f646069f751151279b848a). 


\section{Supplementary Files}




\section{Figures}


Developmental process of the Grow It! app.

\begin{tabular}{|c|c|c|c|c|c|c|}
\hline & Timeframe & Mctivity and aim & Descriptives & Sample & Methad & Lessans Iearaed \\
\hline \multirow{2}{*}{$\frac{5}{3}$} & Ment & 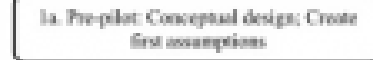 & $\mathrm{N}=10$ & Rescaxh san & mervicms & $\begin{array}{l}\text { Paper hovel proweype asd } \\
\text { wirchams }\end{array}$ \\
\hline & $\mathrm{Mug}_{306}$ & 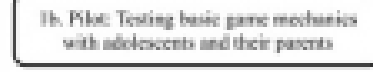 & $N-21,47 ., \pi \leqslant \operatorname{bog} x, N_{-}=14.76 .5 D_{-}=1.95$ & Coeveniknee & ESM k arvey & 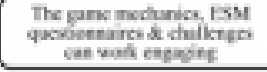 \\
\hline & \multirow{3}{*}{ lave } & \multirow{3}{*}{ 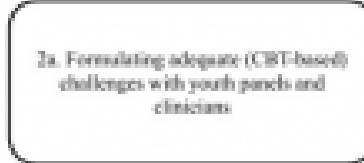 } & $N-6$, Wh boy, agod 19.18 & $\begin{array}{l}\text { Mdvinary beand } \\
\text { cillhe }\end{array}$ & \multirow{3}{*}{$\begin{array}{l}\text { Inknises d } \\
\text { feeses poups }\end{array}$} & \multirow{3}{*}{ 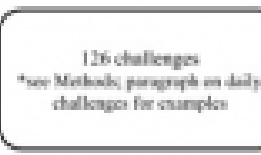 } \\
\hline & & & 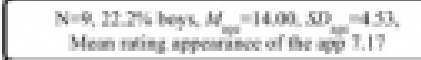 & $\begin{array}{l}\text { Abliery bourd } \\
\text { ditilisn }\end{array}$ & & \\
\hline & & & $\mathrm{N}=11$ & Clasciens & & \\
\hline t & \multirow{2}{*}{$\begin{array}{l}\text { Nowernber } \\
\text { sise }\end{array}$} & 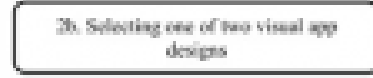 & 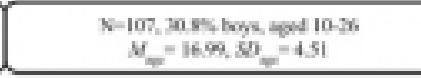 & Contritense & Sarroy & 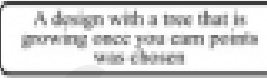 \\
\hline$\frac{1}{2}$ & & 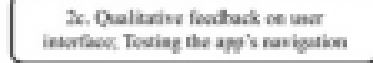 & 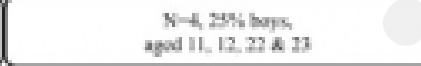 & Contariense & Irtanicens & 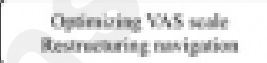 \\
\hline & 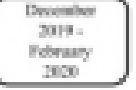 & 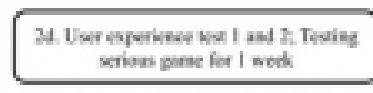 & $\mathrm{N}-23$ & Conrutiense & 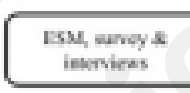 & 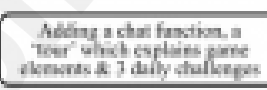 \\
\hline & Fatsongen & 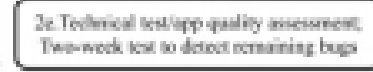 & $\mathrm{N}=10$ & Rocarab tear & ESM A intervions & 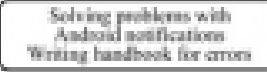 \\
\hline
\end{tabular}


Nickname.

\section{PROFILE}

You will remain anonymous throughout the game, but you can create a nickname!

PRIGKLY

DIZZY

LUGKY

REFRESH
DRAGON

CHICKEN

LAMA

REFRESH

DIZZY GHIGKEN

\section{FURTHER}


Chat function with positive stickers.

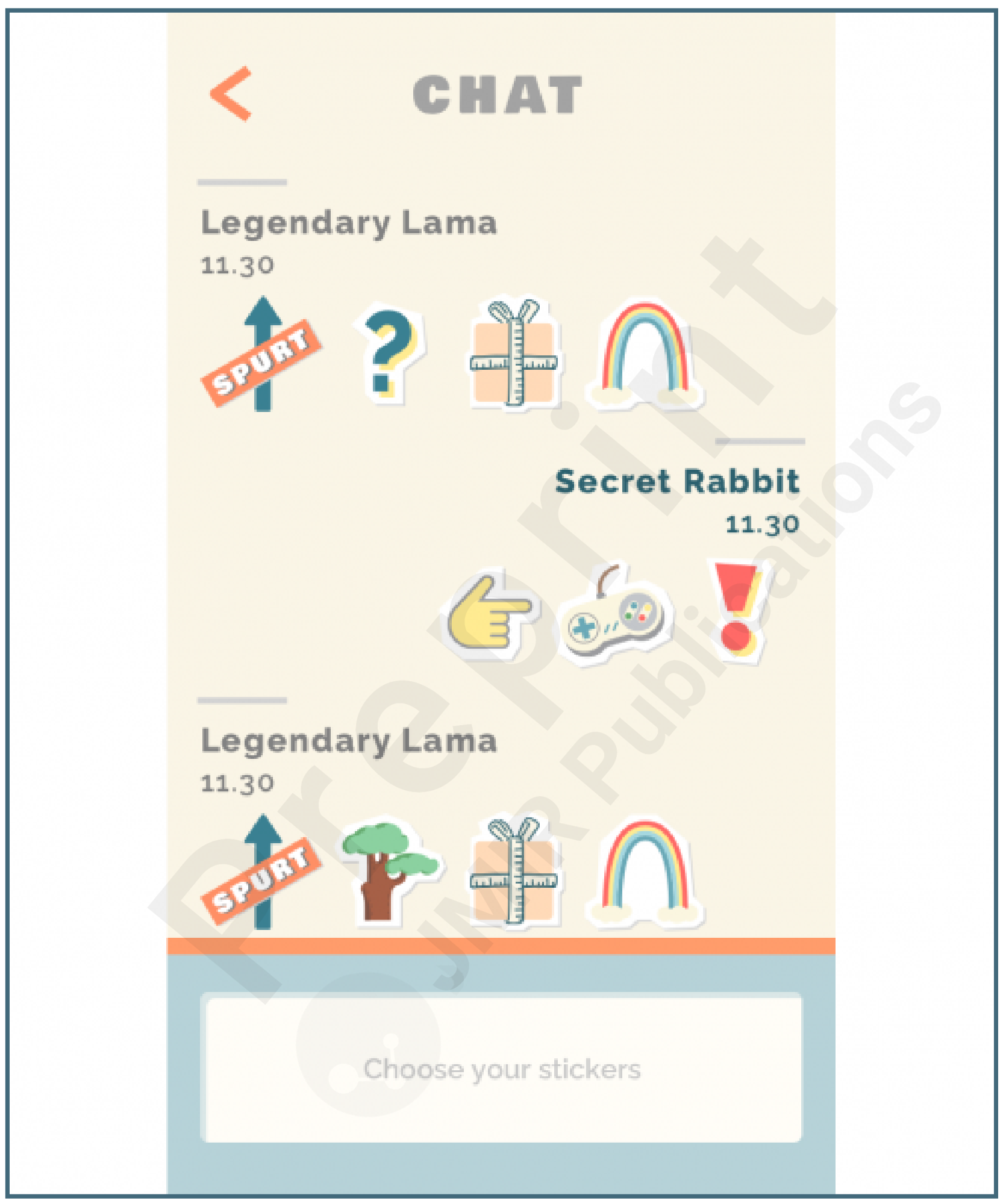


Comparing own tree to trees of other teams.

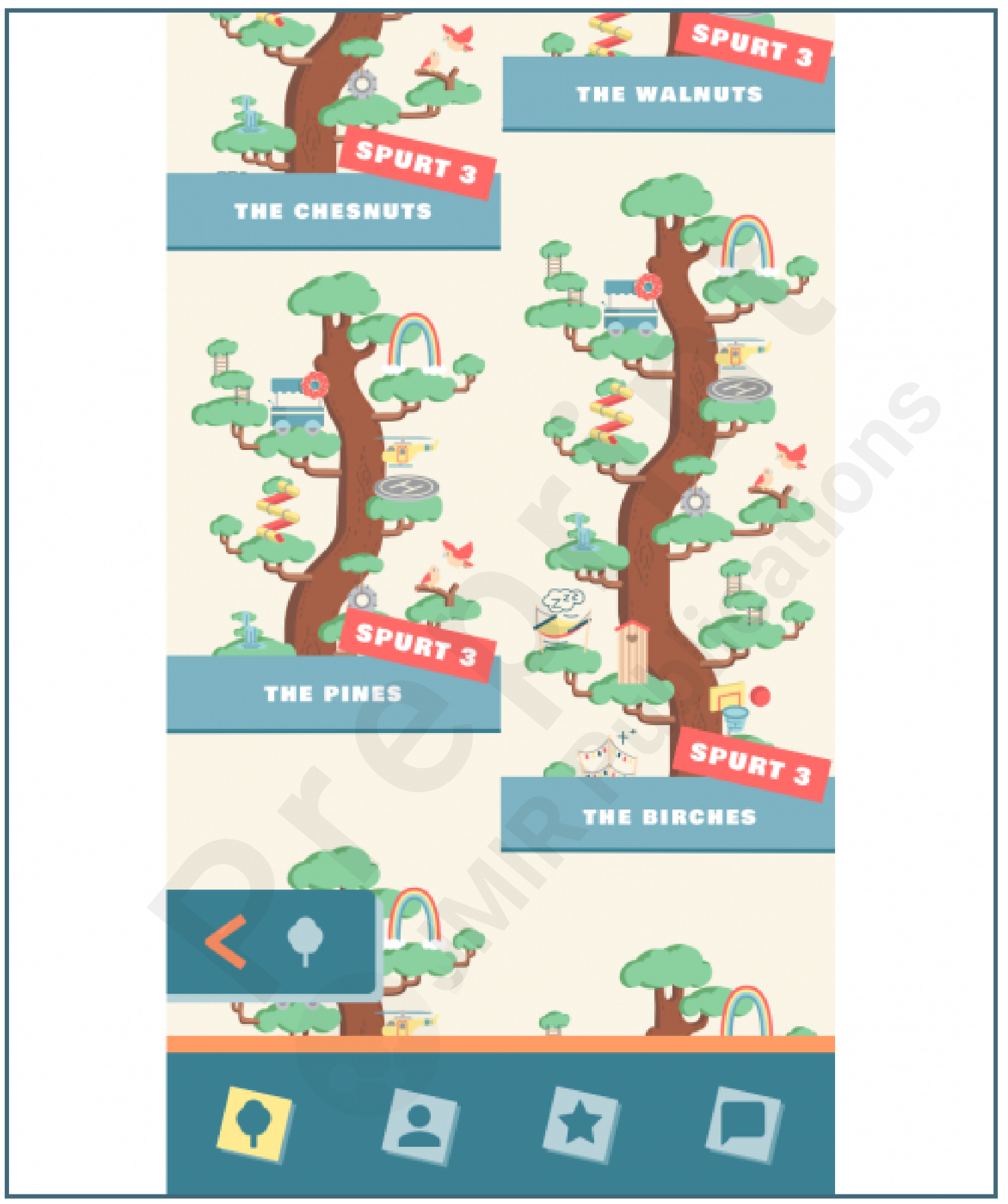


Receiving a gift.

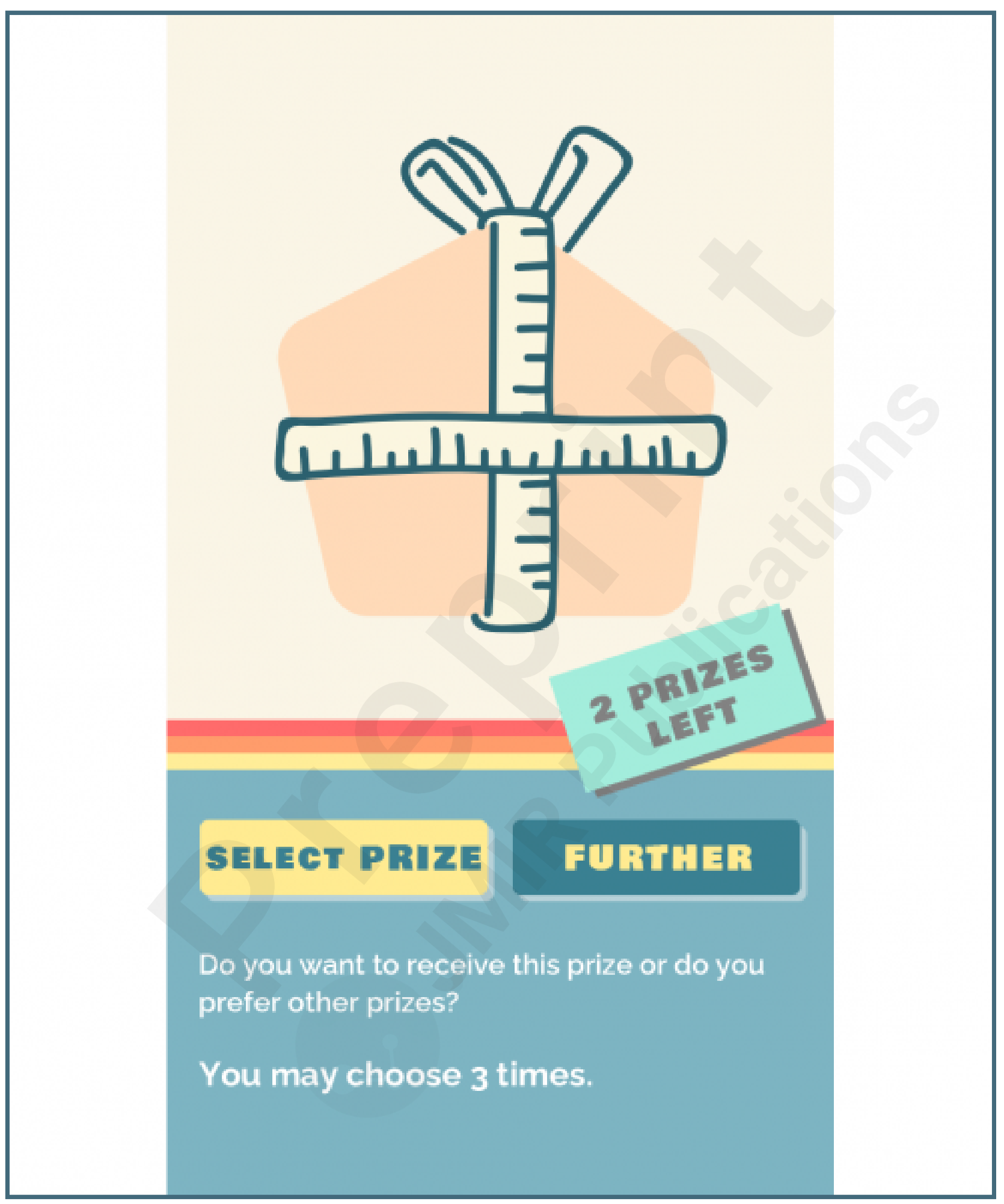


Tree decorated with gifts.

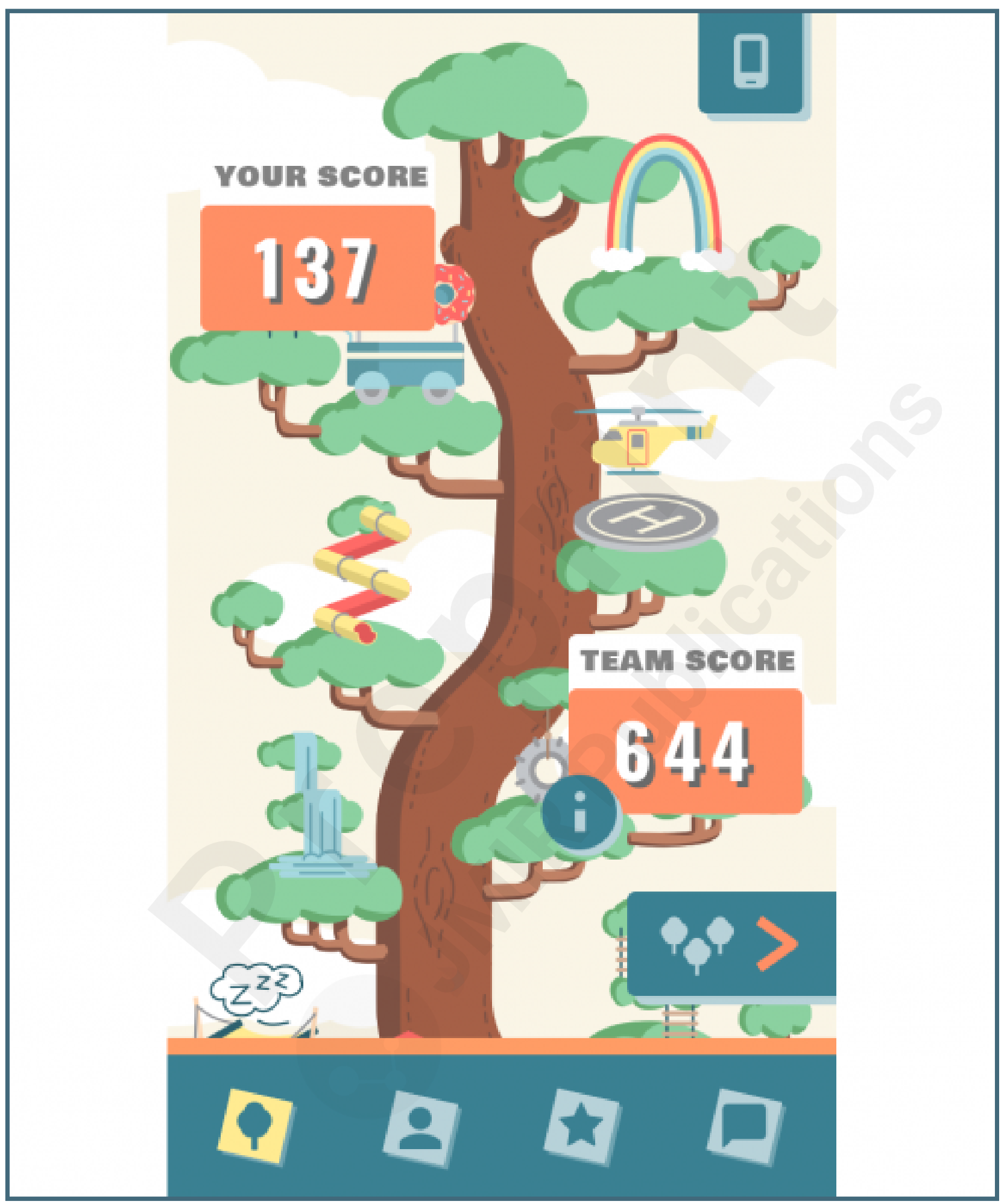




\section{Overview of earned points.}

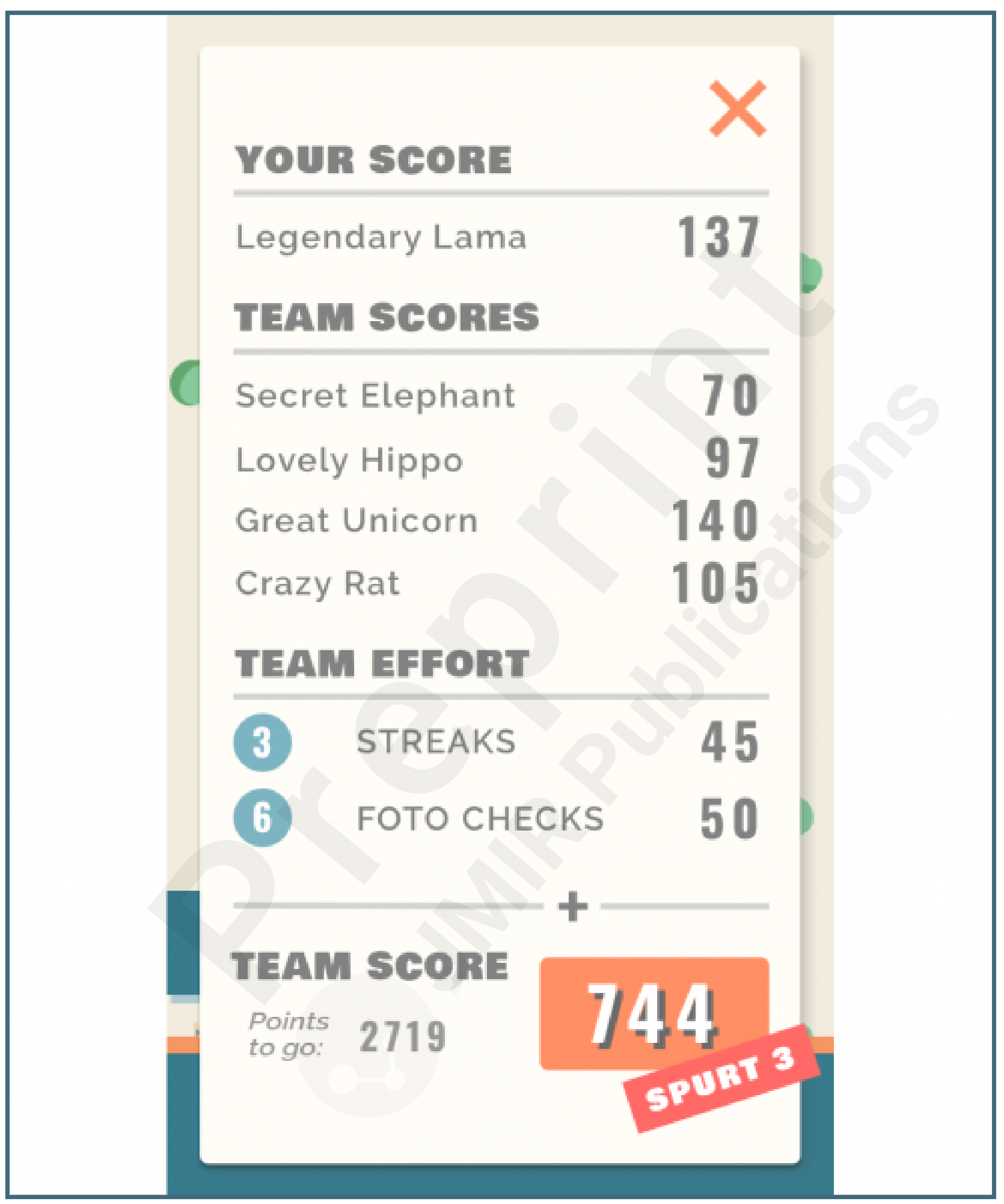


Profile page with the number of completed questionnaires.

\section{PROFILE LEGENDARY LAMA}

\section{TODAY}

Completed 1 of 2 questionnaires

Challenge: done

FR 1/11

Completed 1 of 3 questionnaires

Challenge: done

\section{TH 31/10}

\section{Completed all questionnaires}

\section{WE 30/10}

Completed 6 of 7 questionnaires

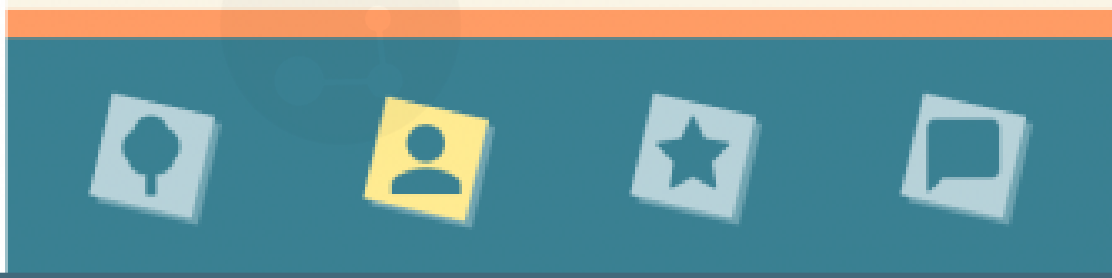


Examples of daily Experience Sampling Method questions.

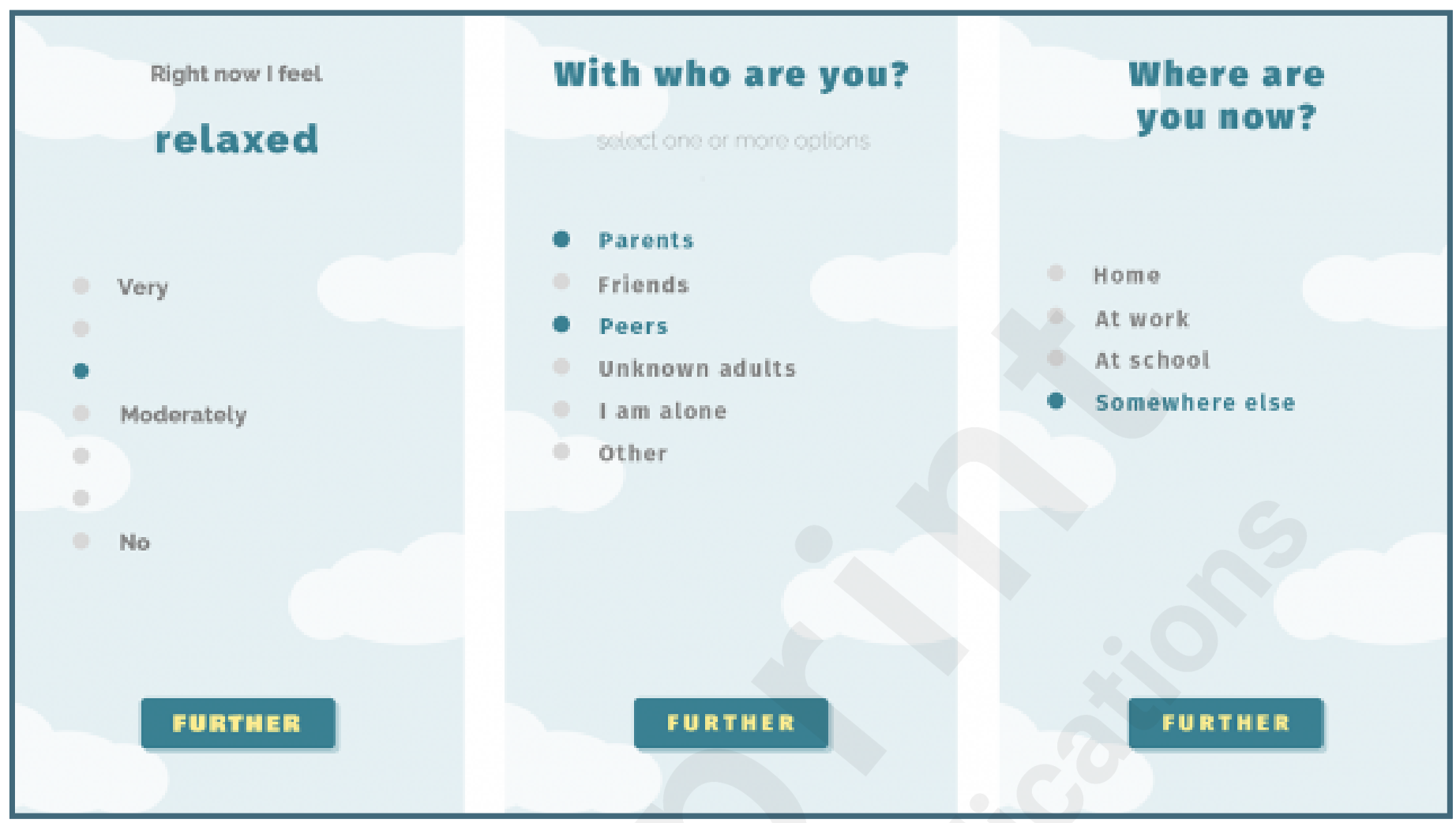


Daily challenge.

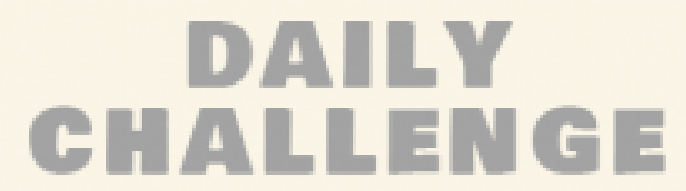

Pick a challenge!

\section{BAKE A GAKE}

\section{WHO ARE YOU}

\section{Dogs aurzz}

\section{Earn extra points?}

Do the photo check!

\section{固 PHOTO CHECK}

